Western University

Scholarship@Western

Africa Western Collaborations Day 2020

Abstracts

Africa Western Collaborations Day

2020

\title{
Antenatal Care Utilization in the Fragile and Conflict-Affected Context of the Democratic Republic of the Congo
}

\author{
Bianca R. Ziegler \\ Western University, bziegle2@uwo.ca \\ Moses Mosonsieyiri Kansanga \\ Western University, mkansang@uwo.ca \\ Yuji Sano \\ Nipissing University \\ Joseph Kangmennaang \\ University of North Carolina \\ Daniel Kpienbaareh \\ University of Western Ontario, dkpienba@uwo.ca
}

See next page for additional authors

Follow this and additional works at: https://ir.lib.uwo.ca/awc_abstracts

Part of the Maternal and Child Health Commons

\section{Citation of this paper:}

Ziegler, Bianca R.; Kansanga, Moses Mosonsieyiri; Sano, Yuji; Kangmennaang, Joseph; Kpienbaareh, Daniel; and Luginaah, Isaac, "Antenatal Care Utilization in the Fragile and Conflict-Affected Context of the Democratic Republic of the Congo" (2020). Africa Western Collaborations Day 2020 Abstracts. 24.

https://ir.lib.uwo.ca/awc_abstracts/24 


\section{Authors}

Bianca R. Ziegler, Moses Mosonsieyiri Kansanga, Yuji Sano, Joseph Kangmennaang, Daniel Kpienbaareh, and Isaac Luginaah 


\title{
Antenatal Care Utilization in the Fragile and Conflict-Affected Context of the Democratic Republic of the Congo
}

Bianca R Ziegler ${ }^{a, b}$, Moses Kansanga, ${ }^{a, b}$, Yuji Sano ${ }^{c}$, Joseph Kangmennaang ${ }^{d}$, Daniel Kpienbaareh $^{\mathrm{a}, \mathrm{b}}$, Isaac Luginaah ${ }^{\mathrm{a}, \mathrm{b}}$

${ }^{a}$ Department of Geography, Western University, 1151 Richmond Street, London, Ontario, N6A 3K7, Canada benvironment Health and Hazards Lab, Western University, 1151 Richmond Street, London, Ontario, N6A 3K7, Canada ${ }^{\mathrm{c} D e p a r t m e n t ~ o f ~ S o c i o l o g y ~ a n d ~ A n t h r o p o l o g y, ~ N i p i s s i n g ~ U n i v e r s i t y, ~} 100$ College Drive, Box 5002, North Bay, ON, P1B 8L7, Canada

${ }^{\mathrm{d} D e p a r t m e n t}$ of Geography and Earth Sciences, University of North Carolina Charlotte, 9201 University Rd, Charlotte, NC, 28223, United States

\begin{abstract}
Maternal mortality represents one of the widest gaps between developed and developing countries. Ninety-nine percent of maternal deaths occur in developing countries, with over half occurring in sub-Saharan Africa. This health indicator became a global priority when the United Nations' Sustainable Development Goal 3.1 set out to decrease the global maternal mortality rate to less than 70 per 100000 births by 2030. In the Democratic Republic of the Congo, 473 of every 100000 women who give birth die due to pregnancy-related complications. These deaths could be prevented through enhanced utilization of antenatal care services and skilled birth attendants. However, amid prolonged conflict, violence, and authoritarian governments, women living in the Democratic Republic of the Congo face difficulties accessing maternal health services. This study examined the utilization of antenatal care and skilled birth attendants in the Democratic Republic of the Congo using multivariate binary logistic regression. This study provides an indication of the state of care within this region and the influence of conflict and gender inequality as well as environmental, population, and behavioural factors on utilization. The findings show that women living in regions within the Democratic Republic of the Congo with extremely high levels of prolonged conflict were significantly less likely than those in regions with moderate levels of conflict to have their first visit within the first trimester
\end{abstract}


$(\mathrm{OR}=0.29, \mathrm{p}<0.01)$, and to have all four antenatal care visits $(\mathrm{OR}=0.46, \mathrm{p}<0.01)$. Overall, women in regions with extremely high levels of conflict $(\mathrm{OR}=0.41, \mathrm{p}<0.01)$ were less likely to meet the World Health Organization's antenatal care recommendations compared to those in regions with moderate levels of conflict. Interestingly, women in regions of high $(\mathrm{OR}=1.86, \mathrm{p}<0.05)$ and extremely high $(\mathrm{OR}=2.41, \mathrm{p}<0.05)$ conflict were more likely to deliver in a hospital.

Furthermore, results indicate that gender-based violence, autonomy, education, watching television, marital status, wealth, and parity emerged as significant factors which were associated with differences in antenatal care and skilled birth attendant utilization. This study suggests that conflict-affected countries, such as the Democratic Republic of the Congo, require contextspecific interventions if progress is to be made towards achieving Sustainable Development Goal 3.1.

Keywords: Conflict; Antenatal Care Utilization; Skilled Birth Attendant; Maternal Mortality; subSaharan Africa; Democratic Republic of the Congo; Sustainable Development Goals

\section{Citation}

Ziegler, B. R., Kansanga, M., Sano, Y., Kangmennaang, J., Kpienbaareh, D., \& Luginaah, I. (2020). Antenatal care utilization in the fragile and conflict-affected context of the Democratic Republic of the Congo. Social Science \& Medicine, 262, 113253. doi:10.1016/j.socscimed.2020.113253 